\title{
Reseña de Cavalletti (2011/2015) Sugestión. Potencia y límites de la fascinación política
}

\author{
Marcos Bonet \\ Universidad de Valencia
}

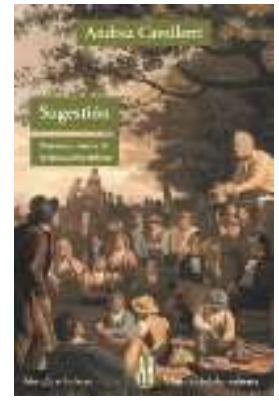

Cavalletti, Andrea (2011/2015). Sugestión. Potencia y límites de la fascinación política. Buenos Aires:

Adriana Hidalgo editora.

ISBN: 978-84-15851-60-8

La editora Adriana Hidalgo parece apostar por Andrea Cavalletti ya que Sugestión. Potencia y límites de la fascinación política $(2011 / 2015)$ es el tercer libro del autor que aparece en su editorial, precedido por Mitología de la seguridad. La ciudad biopolítica (2005/2010) y Clase. El despertar de la multitud (2009/2013). A primera vista, podría parecer que Cavalletti, mediante Sugestión. Potencia y límites de la fascinación política, va a seguir profundizando en algunos topos foucaltianos, al igual que hizo en las otras dos obras aquí citadas. Sin embargo, no es así. En este sentido, el título del libro es engañoso, sobre todo la segunda parte del mismo. El caso es que Andrea Cavalletti intenta mostrar una genealogía del poder político como sugestionador de las masas remontándose a la teoría del magnetismo animal de Franz Anton Mesmer y es esta historia, la del magnetismo animal, la que consigue eclipsar toda referencia o alusión al objetivo principal del ensayo.
De esta manera, afortunadamente, Cavalletti consigue narrarnos una historia sobre el magnetismo animal y sus derivados muy interesante y estimulante a pesar de que los puntos principales de su tesis queden deslavazados a lo largo del texto. Es por esto que podríamos obviar la segunda parte del título, ya que el libro no se termina decantando por ahí, y quedarnos con que todo es «sugestión".

La novela corta de Thomas Mann Mario y el mago, publicada por primera vez en 1930 (1930/1945), nos acompaña a lo largo de todo el ensayo de Cavalletti. En 1926, dos años antes de obtener el premio Nobel de literatura, Thomas Mann y su familia están de vacaciones en una zona costera en Italia, allí asisten a un espectáculo de hipnosis que inspirará el relato Mario y el mago. La crítica literaria ha señalado dos cosas sobre Mario y el mago: la maestría del escritor, ya demostrada en su obra anterior, para retratar ambientes psicológicamente llenos de sutileza y el aspecto de 
crítica y condena al fascismo italiano que puede interpretarse de la lectura del relato. En el caso de Mann, el poder hipnótico, que despliega el hipnotizador Cipola sobre el público asistente al espectáculo, es trasunto del poder autoritario del fascismo sobre el pueblo italiano. Este uso literario de la hipnosis por parte de Mann no es nuevo, algo parecido se ha apuntado en los casos de Ernst Theodor Amadeus Hoffmann y George Du Maurier, para el primero los poderes mesmericos articulados en su relato $E l$ magnetizador (1814/2009) han sido vistos como el poder absolutista napoleónico, en el caso de Du Maurier, el poder representado por el malvado Svengali en su novela Trilby (1894/1995), refleja el poder de los grupos judíos con influencia política, económica y social. La tesis de Cavalletti intenta ir unos pasos más allá, no es que el magnetismo animal y la hipnosis sirvan literariamente para mostrar los peligros del poder autoritario, sino que el poder autoritario ejerce su influencia en las personas mediante el mismo mecanismo por el que el magnetismo animal y la hipnosis funcionaban, por el mecanismo de la sugestión.

Como ya he dicho, el punto fuerte del libro es la historia del magnetismo animal que Cavalletti articula con un estilo fresco, literario, agudo e inteligente. Pero cuidado, no es una historia del magnetismo animal para principiantes, el texto carece de notas explicativas y el lector, para no perderse, tiene que conocer de antemano la historia general del magnetismo animal y a sus personajes principales. Se nota que Cavalletti se sitúa del lado de los magnetizadores (revolucionarios) y en contra de los poderes conservadores (corona, iglesia, academia) que los combaten. También es de agradecer (intelectualmente) que en ningún momento use la anacrónica y absurda palabra de "pseudociencia" para referirse al magnetismo animal o la hipnosis, error muy habitual en supuestos historiadores del tema. Además de los actores imprescindibles en cualquier historia del magnetismo animal y de la hipnosis como Mesmer, Puysegur, Faria, Charcot, Bernheim o Freud nos encontramos con otros no $\tan$ conocidos e igualmente interesantes como Teste, Carra, Bergasse, Villers, Dupotet, Deleuze y Delboeuf, entre otros. En este sentido, nos encontramos con una pléyade de autores y obras (apuntadas extensamente en la bibliografía) que satisfará enormemente al lector buscador de fuentes. Sin embargo, el ensayo histórico de Cavalletti se circunscribe al caso de Francia, incluso en casos de personajes no franceses, como Faria o Freud, estos son presentados en relación a Francia. Los puntos fuertes del trabajo de Cavalletti son: la lucha entre las designadas comisiones reales para investigar el magnetismo animal y Mesmer; la genealogía de algunos temas centrales del psicoanálisis en base a comprensiones del propio Freud en torno a la hipnosis; la lucha entre dos epistemologías rivales en torno a la hipnosis como fueron la escuela de Nancy y la Salpetriere; y la indagación de diferentes teóricos sobre que los fenómenos relacionados con el magnetismo animal y la hipnosis podían explicarse mediante la sugestión. Añadamos a esto que el ensayo de Cavalletti está enriquecido con las reflexiones que algunos prominentes pensadores y filósofos han tenido sobre el magnetismo animal, la hipnosis y la sugestión. Entre ellos, Schopenhauer, Hegel, William James y Bergson. También encontramos referencias al magnetismo animal en la cultura popular, más allá del relato de Mann, como la novela de Emilio Salgari El falso brahmán $(1911 / 1979)$ o la película Whirlpool (Preminger, 1949).

En definitiva, un ensayo histórico sobre el magnetismo animal imprescindible para los interesados en el tema, de lectura amena (exceptuando unas pocas ocasiones en que la traducción ha sido errónea y dificulta la lectura), bien equilibrado y que demuestra que los estudios sobre estas materias, lejos de estar agotados, siempre puede ser abordados con nuevas perspectivas.

\section{Referencias}

Cavalletti, Andrea (2005/2010). Mitología de la seguridad. La ciudad biopolítica. Buenos Aires: Adriana Hidalgo editora.

Cavalletti, Andrea (2009/2013). Clase. El despertar de la multitud. Buenos Aires: Adriana Hidalgo editora.

Du Maurier, George (1894/1995). Trilby. London: Penguin.

Hoffmann, Ernst Theodor Amadeus (1814/2009). El magnetizador. En Carmen Bravo-Villasante (Ed.), Cuentos 1 (pp.178-210). Madrid: Alianza.

Mann, Thomas (1930/1945). Mario y el mago. Barcelona: Victoria.

Preminger, Otto (productor y director). (1949). Whirlpool. [Cinta cinematográfica]. Estados Unidos: 20th Century Fox. 
Salgari, Emilio (1911/1979) El falso brahmán. Madrid: Susaeta.

MARCOS BONET

Universidad de Valencia

DIRECCIÓN DE CONTACTO

bonetsafont@gmail.com

FORMATO DE CITACIÓN

Bonet, Marcos (2016). Reseña de Cavalletti (2011/2015) Sugestión. Potencia y límites de la fascinación política. Quaderns de Psicologia, 18(2), 109-111.

http://dx.doi.org/10.5565/rev/qpsicologia.1355 